\title{
The Curse Of A Size: Socio-Cultural Conception Of Dwarfism And Effects On Political Participation In South-Western Nigeria
}

\author{
Azeez O. Olaniyan \\ Department of Political Science, Ekiti State University, Ado Ekiti, Nigeria
}

\begin{abstract}
The notion of dwarfs as inferior members of the society is a long-held belief amongst the Yoruba ethnic group of south-western Nigeria. By virtue of their size, dwarfs are objects of amusements and ridicule and denied political and leadership opportunities. They cannot become kings, hold chieftaincy titles; serve as heads of family, village heads or occupy leadership positions. In spite of persistence of this discrimination, there is a dearth of research on dwarfs' socio-political life. And this raises some pertinent questions: what is the socio-historical conception of dwarfism among the Yoruba people? What are the socio-cultural barriers placed on the dwarfs? What are the effects of these on dwarfs' psycho-political participation as members of the society? And, how do they express their socio-psychological and political affinities, affiliations, preferences, and feelings? Using participant observation, in depth interviews with key informants and archival search, this study seeks to interrogate these problematic.
\end{abstract}

Keywords: Dwarfs, Stigma, Politics, Exclusion, Southwestern Nigeria

\section{Research Background}

Down the ages and across cultures, dwarfs are often a butt of humour and curiosity and often affixed with an in-born or ascribed stigma that seldom change (Goffman, 1963, Adelson, 2005, Backstrom, 2012). Dwarfism is said to be a genetic condition resulting in short stature (Ablon, 1984). Thus, a dwarf is someone who, as a result of genetic malformation, falls under the height of about $140 \mathrm{~cm}$ (55.1 in, 4.6ft) in women and about $150 \mathrm{~cm}$ (59.1 in, 4.9ft) in men (Haberer, 2010:3). The exact number of dwarfs is relatively unknown but dwarfism is said to occur in 1 child per 10,000 births, appearing in about 200 types falling under proportionate and disproportionate categories, which is neither race-bound nor culture-specific (Ablon, 1984, Haberer, 2010).

Corresponding author: Azeez O. Olaniyan

olaniyan444@yahoo.com

Published online at http://IJDS.ub.ac.id/

Copyright (C) 2019PSLD UB Publishing. All Rights Reserved
Dwarfs belong to the minority group in the society but this notwithstanding; they remain part of humanity and therefore entitled to fundamental rights. But what obtains is a universal denial of the dwarfs of these rights irrespective of their socio-cultural lineage or educational attainment.

Dwarfism, within the context of disability discourse, borders on the twin concepts of identity and stigma. Stigma is a socially constructed frame through which physical disabilities are conceptualised and then branded as different and subsequently devalued (Phemister and Crewe, 2004:33, Chanzanagh, Piri and Garjan, 2012:176). It boils down to the question of whether dwarfism as a "discursive identity" (Kruse, 2003:496) and dwarfs as socially constructed disables (Ablon, 2005) possess socio-political rights in a world dominated by tall men who have constructed a mental model of height as a yardstick for political participation.

The universality of dwarfism and the derision it evokes across ages and climes have triggered the emergence of several perspectives. Some have examined these set of people from the gender perspective (Gremillion, 2005); from 
social discrimination angle (Kruse, 2003); from historical evolution (Ablon, 2005, Kruse, 2003); and from entertainment perspective (Olaiya, 2013). Mine is from the angle of politics. And what I set out to do is to interrogate how Yoruba people of south-western Nigeria conceptualize dwarfism and how such conception impact on the political participation of the dwarfs both in the traditional and modern spheres. This is because, in the traditional Yoruba society, dwarfs are forbidden from holding leadership positions; they cannot be kings; they cannot hold chieftaincy titles; they are not permitted to assume the role of family head; they cannot be appointed to head villages and neither can they be allowed to represent the people in any capacity (Idowu, 1962, Ekanola, 2006:42). They are therefore excluded from the political process both in the traditional and modern times. In other words, Yoruba people conceptualize these set of people as inferior. And this historical and cultural construction of inferiority has given rise to total exclusion from the political process. Despite advancement in civilization and democracy, this practice continues. In spite of this long practice, no major research work has emerged on the socio-political life of the dwarfs in south-western Nigeria. The pertinent questions arising are: What is the socio-cultural conception of dwarfism in Yoruba land? What are the historical and cultural bases for the conception? Of what consequence is this conception on the life of the dwarfs in the political process? What is the contemporary relevance of the conception and practice to the whole discourse on power and leadership? What is the linkage between body size and politics?

\section{Methodology}

A combination of historical, descriptive and interpretative method of data collection and analysis was adopted. The study made use of primary and secondary data. The primary data was generated through interviews. Fieldwork was carried out among the Yoruba ethnic group in various towns in South-Western Nigeria, which is made up of six states of Ekiti, Ondo, Oyo, Ogun, Osun and Lagos. The interviews targeted four categories of people: The first are If a priests who are regarded as the custodian of Yoruba culture. The second are some elderly members of the Yoruba ethnic group who provided valuable information, and practically supported the views of Ifa priests. The third are the dwarfs themselves. The fourth are members of the public. The interviews were both purposive and random. Ifa priests, elders and dwarfs were purposively selected in different locations, while members of the public were randomly picked for interview. The dwarfs were interviewed individually in different towns and in large grouping at Ebute Ilaje, in Bariga, Somolu local government area of Lagos state. Specifically, the dwarfs were asked to tell their life history in relation to politics. Information collected through life experience formed the bedrock of the primary data. Secondary data was sourced from various relevant journals, texts, newspapers, magazines, archival materials, unpublished theses, dissertations, and the internet. Data collected was subjected to qualitative analysis. One way of doing this is by engaging in content analysis. Content analysis technique allows a researcher to make inferences by objectively and systematically identifying specified characteristics within a text. Rigorous content analysis via checking and cross checking of facts eliminated possible manipulation of data and researcher biases.

\section{Towards a theoretical framework}

Scholars like Joan Ablon, Kruse, Helen Gremillion and Haberer have written copiously on this special set of human beings from different perspectives. From their writings, we got to know that dwarfism is a genetic condition resulting in short stature. Thus, a dwarf is someone who, as a result of genetic malformation, falls under the height of about 140 $\mathrm{cm}(55.1 \mathrm{in}, 4.6 \mathrm{ft})$ in women and about $150 \mathrm{~cm}$ (59.1 in, 4.9ft) in men (Haberer, 2010:3). The exact number of dwarfs is relatively unknown but dwarfism is said to occur in 1 child per 10,000 births, appearing in about 200 types falling under proportionate and disproportionate categories (Ablon, 1984, Haberer, 2010). Dwarfs belong to the minority group in the society but this notwithstanding; they remain part of humanity and therefore should be studied.

A review of extant literature shows that the existence of dwarfs is neither ethnic-bound nor culture specific. It is a universal presence. According to Ablon, even before there was a written history, dwarfs appeared in the artworks of many cultures. Images of dwarfs are among participation in south-western Nigeria. Indonesian Journal of Disability Studies (IJDS).2019: Vol. 6(2): PP 250258 
the oldest artefacts extant: They are depicted in ancient stone and clay funerary sculpture in Egypt, India, China, and the Mayan civilizations; they are highlighted in the legends and myths of every nation (Ablon, 1984:1).

The universality of the occurrence of dwarfs have triggered intense debate, and one of such contention in the extant literature of disability studies is whether dwarfism is a matter of difference or defect (Kennedy, 2003). For a long time, dwarfs were interrogated on the basis of difference, until recent time, when the disability school won the debate (Kruse, 2003). Increasingly in the recent time, dwarfs are seen from the prism of disability. Two major theoretical perspectives have emerged in disability discourse. These are the biomedical and the social construction theories. The biomedical perspective holds that dwarfism is a genetic disorder, which results in proportionate and disproportionate forms of dwarfism. The perspective dwelt largely on separation of body from the social processes (Cornell, 2011).

But from the 1980s, there emerged the social-construction approach that insists on a merger of the biological and the social (Roberts, 2000); for the notion of disability operates within the context of socio-cultural construction (Kirk, 1993, Meekosha, 2004, Connell, 2011). Those who subscribe to this perspective argue that dwarfism is a socially constructed orientation in the sense that their disability is not the absence of function of parts of the body but simply a perception that something is wrong with their size (Ablon, 2005). This perception hinges on the construction of normal man as fitting into Le Corbusier's Modular of normal person "as a standing, muscular, strong male, six feet in height" (quoted in Kruse, 2003:497). Suffice to say that non-fitting into this prism makes the person a disable (Kruse, 2003:497). In essence therefore, the disability conception of dwarfism is more of a socio-cultural construct. Within the context of socio-cultural construction, dwarfism borders on the twin concepts of identity and stigma. It is seen as an identity of shortages (both of body and mind). Cultural construct of dwarfism makes it a case of disability. It goes with stigma. Stigma is a socially constructed frame through which physical disabilities are conceptualised and then branded as different and subsequently devalued (Phemister and Crewe,
2004:33, Chanzanagh, Piri and Garjan, 2012:176).

The issue in this study therefore is the question of whether dwarfism as a "discursive identity" (Kruse, 2003:496) and dwarfs as socially constructed disables (Ablon, 2005) possess socio-political rights in a world dominated by tall men who have constructed a mental model of height as a yardstick for political participation. We need to ask some questions again: how do the Yoruba people conceptualize dwarfs (as difference or disability?); second, how do the dwarfs categorise themselves? Which of the perspectives fit into this discourse?

\section{Results}

The Yoruba people inhabit the southwestern part of Nigeria. They have a long and well-established traditional political system that borders on a well-organized kingship system (Lloyd, 1954:366-384). Each town is headed by kings who are selected from established lineage by kingmakers. Kings are assisted by chiefs of varying ranks. Chiefs emerged either through hereditary succession or by appointment by the kings. The traditional political system is therefore one in which the kings act as the president and the chiefs the cabinet members. They form the power configuration of the towns and villages in the traditional sense of it. Although the criteria for selection of kings and chiefs varies from town to town, yet the requirements for ascension to the throne or the stool in any Yoruba land is same. They include membership of a ruling/chieftaincy house, high moral standing and non-physical disability. Those on the disability list include such people as the deaf, the dumb, the lame, the blind, the hunchback, albino and the dwarfs. While the first five set of people are distinguishable as physically disabled, what of the last two? Do differences in skin pigmentation and body size constitute disability? The preclusion of these set of people from leadership position has cosmic backing, according to Chief Ifayemi Elebubon (Interview 12 August 2014). My focus is on the dwarfs and not on albinos.

The first finding here is that dwarfs are regarded as disabled/deformed in the Yoruba traditional context. Thus, placing the disables in the rank of the disables precludes them from the political process in the traditional sphere of the 252

Cite this as:

Azeez O. Olaniyan. The curse of a size: socio-cultural conception of dwarfism and effects on political participation in south-western Nigeria. Indonesian Journal of Disability Studies (IJDS).2019: Vol. 6(2): PP 250258 
society. In Yoruba culture, deformity is regarded as a curse from god, or even an idol of gods. The question then is: are the dwarf idols? According to Chief Ifayemi Elebubon (Interview 12 August 2014),

Truly, they are not idols per se but they are a semblance of idols "Eni-Orisa ni won" "they are special people of gods' In the olden days, they are forbidden people because of their peculiarities. There is a particular verse of the literary corpus known as the 'ODU IFA' divination system which traced their predestination to be an instrument or semblance of idols as 'Special people of gods' due to their misdemeanors in the Yoruba traditional history in the past.

The import of the forgoing is that dwarfism is conceptualized as a punishment from the gods for offence committed in the cosmos. Therefore, people of this stature are regarded as special creation of the gods, and thus different from the rest of human beings. References to them as Eni Oosha, symbolizes something that belong to the gods. Since they are so specially created, they should be devoted to serve the gods either as servants or to be offered as sacrifice to the gods. Since they are not regarded as normal human beings, they are can be willingly offered to the gods as sacrifices in the ancient times. There is therefore the submission of difference in the conception.

The second finding is that they are forbidden from assuming leadership position. According to Professor Odeyemi (Interview 12 September, 2014) they cannot become kings or leaders of any associations because of their peculiarities and their ancestral lineage in the Yoruba traditions which likened their personality to being deformed or disabled persons. It is argued that anybody that must lead anywhere in the Yoruba land must be 'ablebodied'. Again, Chief Elebubon (Interview 12 August 2014) submits that

Yes! They cannot become King or leader of any association because of their peculiarities and their ancestral lineage in the Yoruba traditions which likened their personality to being deformed person anybody that must lead anywhere in the Yoruba land must be 'ABLE BODY' not idol-like being 'ENI-ORISA'. As such, they are denied, by virtue of their physical deformities, the full opportunities open to normal people. They are not allowed, for example, to function as heads of household, village heads, or kings. After death, they cannot become ancestors because they are not buried in the lineage grave site but in the evil forest. Based on my sense experience for decades, I have never seen instances of where dwarfs are allowed to become king or leader any association as far as this Yoruba land is concerned. It has never happened before in the history of Yoruba race. Or have you seen somewhere dwarfs have been allowed to lead or still leading?

Able-bodied here refers to big physical size. To the extent that dwarfs are regarded as not conforming to the 'able-bodied' standard, they are denied the full opportunities open to normal people. They are not allowed, for example, to function as heads of household, village heads, or kings. After death, they cannot become ancestors because they are not buried in the lineage grave but in the evil forest.

The third finding is that there is a contemporary practice of exclusion of these set of people among the people. This has to do with the general size of the body. All respondents agree that it would be a misnomer for a dwarf to lead people of normal height. The pattern of exclusion from becoming kings or holding chieftaincy titles is also reflected in inability to present them for election or even vote for them when they contest for election.

The fourth point is that this study found out that in the Yoruba society, dwarfism is seen both as a difference and as disability. In other words, there is a marriage of biomedical and the social. The discourse shall make this clearer. However, the dwarfs do not see themselves in the prism of disability; but they have not shown outward rejection when they are lumped as disabled by official policies. More often than not, they are put in the category of disables in official matters in Nigeria.

Some issues emerged from the foregoing. First is that dwarfs are not regarded as normal human beings by the Yoruba people. References to dwarfs as eni oosha is an indication that such creations are not considered normal. This falls in line with general representation of difference. Such different appearances in term of skin pigmentation; hunchbacks and dwarfs are regarded as an abnormal creation by the gods. The belief is that such children are punishment from the gods. This is what is called cultural representation of difference. It is often associated participation in south-western Nigeria. Indonesian Journal of Disability Studies (IJDS).2019: Vol. 6(2): PP 250258 
with stigma, in which carriers of such traits are subjected to curiosity and stigma. The second is that dwarfism is regarded as disability. The belief that deformed person cannot be a leader in Yoruba land is very strong. Dwarfs are categorized in such group of people with deformity. In this wise, dwarfism is culturally represented as disability. Third is that size mattes: According to Professor Abiodun (Interview 7 July 2014), in the Yoruba society, a king or leader of any segment must be of person of size; eyeful and good to behold. By virtue of their size and not so good look, dwarfs are excluded from any leadership position. When a question of why dwarfs are never made to play the role of kings or chiefs in Yoruba drama was posed to Kareem Adepoju (aka Baba Wande) (Interview 12 February, 2015), his reply was that drama must be a reflection of the society, and if they try to do what is clearly against the tradition, nobody will take them serious and such a play may not attract sales. In his elaboration

When you mention king in Yorubaland, people expect to see someone with good physical and imposing figure; someone that commands respect by sheer size of his physique. It will therefore be an aberration to see a dwarf being made a king. It is unthinkable. Nobody will take that kind of play serious and we will lose sales considerably. It can only happen when the whole play is on dwarfs and the dramatis personae are also dwarfs. Drama must mirror the image of the society.

The theatre representation captures the politics of exclusion by the larger Yoruba society. In addition to exclusion from playing the role of kings, dwarfs are also never featured as chiefs, heads of extended family, wealthy person and representative of a community or spokesperson of people. They are only restricted to such roles as messenger, amusement or other peripheral non-serious parts. In Nollywood, dwarfs are put in the category of disabled; and the film industry helped in amplifying the sociocultural representation of disability by the role they are made to play. However, Kolawole Olaiya (2013:137-156) regarded the usage of the disables as one of a beneficial representation, in the sense that it though amplifies the sociocultural conception of inferiority, yet their usage empowers them and increase their social status and privileges. Lastly, the dwarfs do not see themselves as different or deformed. They regard themselves as normal human beings.

\section{Discourses on the conceptualization}

The foregoing raises three major debates: normal versus abnormal; disability versus difference; relevance of size and linkage between body size and politics. Discourses on these posers will be situated within the context of the interviews conducted with the dwarfs at different locations in the area of study.

\section{Normal or abnormal}

Is dwarf a normal person? According to Yoruba tradition, they are not normal. General view of majority of respondents is that dwarfs are abnormal set of people. The abnormality is based on the sizes of their body parts, which as has been argued heretofore, are not in conformity with the standard of a 'normal' person. In the same vein, the bio-medical perspective sees dwarfism as consequent on genetic malformation or malfunctioning. That means in a situation with normal genetic working, a dwarf ought not to emerge. That means if we go by the bio-medical angle, we can then say that dwarfs are abnormal human beings? But the Yoruba conceptualization is not based on bio-medical analysis. Rather, it derived from physical appearance. If this is the case, can we then say that physical appearance connotes normalcy? In the series of interviews conducted, dwarfs see themselves as normal human beings. And that they do not belong to the gods. Some are well educated and earn good living. At the dwarf community in Ebute Ilaje, Bariga, Somolu local government, Lagos, all the dwarfs interviewed said they were not abnormal. In the opinion of Daniel (Interview 11 August 2014), the leader,

We are not dwarfs. We are little people. There is nothing abnormal in us. We have all the same things others have, though in shorter forms. That does not mean we are abnormal. People should not call us abnormal. We can do what others do, only that they don't give us the chance. The dwarfs regard themselves as normal. But can we take their words for it? The idea of what determines normalcy has been discussed in the theoretical section. The dwarfs did not fit into the prism. 


\section{Disability or difference}

Is the case of dwarf a matter of disability or difference? According to Ingstad and Whyte (1995), bio-psychological conceptualization of disability sees it as limitations resulting from dysfunction in an individual bodies and minds. The World Health Organisation (1980) also refers to it as any restriction or lack of ability to perform an activity in the manner within the range considered normal for a human being. Do dwarfs exemplify these definitions? According to Alhaji Tijani Omo Ile Gbemu (Interview 17 September 2014), one of my respondents who happened to be a landlord to a number of dwarfs, "dwarfs are not disabled. They are normal human beings; they are born by people of normal height. They give birth to children who are of normal heights. There is nothing untoward about them. They lived in my house for several years. We interacted freely. They are not Eni Oosha. I can say that categorically". What obtains then is a cultural representation of dwarfism as disability. According to Wendel, "this happened when we consider bodily differences - deviation from a society's conception of normal or acceptable body - that, although they cause little or no functional or physical difficulty for the person who has them, constitute major social disabilities" (Wendel, 1996:44).

My research shows that the size of the dwarf puts limitations to some of things that they can do. For example, a dwarf cannot play football in the midst of tall and energetic people. The size of dwarfs precluded them from being enlisted in the military forces. Also, a dwarf may find it difficult mounting the campaign podium for rigorous electioneering campaigns. Viewed from this angle, we can say there are some elements of disability. However, such disability is not necessarily a function of the mind. Many of my respondents are well educated, some with university degrees. The problem of the dwarf is not totally a disability of the body but rather it is the smallness of the body or to put differently, smallness of parts of the body. In this wise, smallness could constitute some form of disability. But does smallness constitute impediments to capability? The examples cited above proves that smallness can really constitute impediments. No doubt in the case of the dwarfs, there are traces of differences and disability. But these are amplified to the state of cultural stereotype. But should that constitute total exclusion from leadership position? If leadership is all about directing and coordinating, does physical appearance matter? One respondent argues that a dwarf cannot lead because people may not be willing to take orders from him/her. This means imposing appearance may be a factor in ascription of leadership, at least within the context of Yoruba traditional political system. What these boils down to is the fact that both the bio-medical and socio-cultural theories of disability are relevant in the discourses on Yoruba conceptualization of dwarfism. Dwarfs are different by virtue of their sizes, and this has a lot of impacts on their political orientation.

\section{The relevance of size}

Of what relevance is body size? This study found this to be at the bottom of the whole discuss on their exclusion from power configuration or power hierarchy both in the traditional and modern spheres. Almost all the dwarfs I interviewed show fair consciousness of politics. They are not apathetic. As argued in the foregoing, the size of dwarfs put some limitations in what they can do. In the modern time, there is no area where this is prevalent than at the realm of politics. Many of the dwarfs I interviewed talked about loving politics and had desires to participate in politics at various levels. However, they all complained of limitations posed by their sizes. They also talked about the stigma they face as major impediments to such adventure. Although the literature shows that political participation is both latent and manifest; this study lays much emphasis on the latter, which includes being membership of political party, standing for election or supporting other candidates; participating in electoral campaigns; voting during elections and given appointive posts after election. This study shows exclusion from virtually all these outward political participations - before, during and after elections.

Pre-election activities involves belonging to political parties, attending party meetings and conventions, competing for votes for primaries and joining campaign teams. Dwarfs are excluded in all these stages. One of my respondents narrates how he once attempted to join a political party but when he went to sign up at a ward meeting, he became object of attention; and he was embarrassed that he had to run back. He never attempted it again. In another vein, 
dwarfs will need to compete with other party members to get nominated to fly their parties' flags during general elections. Few parties will be willing to ever feature them as flagbearers. Ruth James (Interview 18 August, 2014) says "I nurse the ambition to contest for councillorship position in my ward but I know they will never vote for me because of my height. They will make jest of me. I will not even scale through the primary". At the level of campaign, the same level of frustration is always there. They can only be employed to amuse and entertain party supporters during rallies. There are no provisions for dwarfs to even vote. Olu (Interview 12 July, 2014) complained that the table where she will do the thump printing was too high for her.

Another problem is the willingness of electorates to vote dwarfs into office. The story of one of my respondents in Lagos exemplifies the problem of voting for dwarfs, which shows continuity of the Yoruba traditional practice of socio-cultural representation of dwarfs and rejection/exclusion. $\mathrm{He}$ is a fairly-educated politician with a Higher Diploma Certificate in Business Administration. He is very popular within the area. He is also a very strong member of Action Congress (AC), the ruling party in Lagos at the time. In 2012, based on his own assessment of his popularity, he nursed the ambition to govern. He obtained the nomination form to run for the post of chairmanship of Oshodi/Isolo ocal Government Area of Lagos state under the banner of AC. However, in spite of his popularity within the party, he lost to an unpopular candidate at the primary election stage. He was later appointed a Senior Special Adviser on Disabled People to Governor Fashola. The major fact derivable from this case is the issue of rejection by virtue of his size. In my interview with some of his party members, they attested to his brilliance and popularity in the whole of the local government but argued that their party would have lost if he had been presented to be the flagbearer at the general elections. Their argument was anchored on the fact that people would never vote for dwarf. The popularity is attested to by his appointment as an aide to the Governor of the state. Again, by the nature of portfolio given to him, we can see that he was regarded as a disabled person. However, he did not see himself as a disable. The implication here is that no matter the level of educational attainment, the sizes of dwarfs put limitations to what they can aspire to be at the politically sphere.

\section{Body size and politics}

The crux of this discourse on dwarfism bothers on the interface between body size and politics. From the example of the Yoruba traditional practice, we see a strong relationship between the two. In the contemporary life, there is still a strong linkage. A number of studies have emerged on body size and politics. However, the focuses are entirely different from that of this study. Helen Gremillion's work dwelt exclusively on women, and she identified a strong relationship between female body size and conceptualization of beauty in different cultures. Futhi Zikalala's was also on the agelong and cross-cultural politics of discrimination of assessment when it comes to the bodies of men and women. To her, a woman is usually assessed on the basis of size and shape of her body, but when it comes to man, the emphasis is usually on property he possesses, and not his body (Zikalala, 1994). Using the conceptualization of dwarfism in Yoruba traditional and contemporary times as case study, this offers a different dimension by showing a linkage between body size and political inclusiveness and otherwise.

\section{Conclusions}

This study has been devoted to the politics of exclusion of dwarfs in political matter, both at the traditional and modern spheres. It argues that the traditional conception of dwarfs as inferior members of the society is deeply entrenched and has contributed to their exclusion from assuming leadership roles, and even participating in politics in the society. Dwarfs are generally lumped in the categories of disabled or deformed people. The modern conceptualization has not witnessed any changes at all. The study shows how people view disability. Disability is seen as punishment from the gods. In such a situation, such people are branded as evil and excluded. The point then is that how do we accommodate people categorized as disabled. Should people be excluded on perceived incompleteness of their creation?.

The study also shows that the debate on the categorization of dwarfs is still not finally settled. The traditional conception that portrays 
dwarfs as abnormal, different and disabled, by their creation 'unluckiness', explains the entrenchment of politics of exclusion. But the study also shows that dwarfs are not apathetic. They are conscious of politics, only that the size of their bodies and the society have placed limitations on how they can express their political feelings.

In all, the study shows that in determining who leads or who represents, selection criteria will include both objective and subjective factors. While such things as intelligence, education, wealth, lineage of birth, high moral standing, legality could constitute the objective factors; obviously, body size in terms of physical appearance, height, look and stamina will form the subjective. In the contemporary world, we have seen instances of the ascendancy of the subjective factors over the objective ones. My research increasingly reveals the prevalence of leadership selection on the basis of body sizes across cultures, in addition to other factors. What this tells us is that the present behaviour, in some situations, may not be a complete departure from the past.

\section{Acknowledgment}

I acknowledge and thank African Humanities Programme of the American Council for Learned Societies (ACLS) for providing the grants for fieldwork and production of this research work.

\section{References}

Ablon, J. 1984. Little People in America: Social Dimension of Dwarfism. New York: Prager Books

Adelson, B. 2005. "Dwarfs: The changing lives of Archetypal curiosities - and echoes of the past". Disability Studies Quarterly, 25(3)

Adelson, B. 2005. The lives of dwarfs: Their journey from public animosity toward social liberation. Piscataway: Rutgers University Press

Adelson, B. M. 2005. Dwarfism: Medical and Psychological Aspects of Profound Short Stature. Baltimore. John Hopkins University Press

Backstrom, L. 2012. "From the freak show to the living room: Cultural representations of dwarfism and obesity". Sociological Forum, 27(3)

Cite this as:

Azeez O. Olaniyan. The curse of a size: socio-cultural conception of dwarfism and effects on political participation in south-western Nigeria. Indonesian Journal of Disability Studies (IJDS).2019: Vol. 6(2): PP 250258
Chanzanagh, H. E, Akbar, P. \& Garjan, E. A. 2012. "The disabled and their everyday life experiences in Iranian culture". International Journal of Social Sciences and Humanitarian Studies, 4(1): 1309-8063

Cornell, R. 2011. "Southern Bodies and Disability: Re-thinking Concepts". Third World Quarterly, 33(8):1369-1381

Dwarfs Association of Nigeria, http://www.remedyspot.com/showthread.php/1 242624-DAN-(Dwarfs-Association-of-Nigeria)

Ekanola, A. B. 2006. "A naturalistic interpretation of the Yoruba concept of Ori". Philosophia Africana, 9(1)

Goffman, E. 1963. Stigma: Notes on the Management of Spoiled Identity. New York: Simon \& Schuster

Gremillion, H. 2005. "The cultural politics of body size". Annual Review of Anthropology, 34(1): 13-32

Haberer, J. 2010. "The little difference: dwarfism and the media", seminar paper on Communication Research Studies, Norderstedt: GRIN Verlog

Idowu, E. B. 1962. Olodumare: God in Yoruba Belief. London: Longman Ltd

Ingstad, B and Whyte, S. R. 1995. Disability and Culture. Berkeley: Univ. Calif. Press

Kennedy, D. 2003. Little People: Learning to see the world through my daughter's eyes. Pennsylvania: Rodale Books

Kirk, D. 1993. The body, schooling and culture. Geelong: Deakin University Press

Kruse, R. J. 2003. "Narrating intersections of gender and dwarfism in everyday spaces". The Canadian Geographer. 47(4): 494-508.

Meekosha, H. 2004. "Drifting down the gulf stream: navigating the cultures of disability studies". Australian Journal of Human Rights, 15(1): 47-75

Olaiya, K. 2013. "Commodifying the "Sacred," Beatifying the "Abnormal": Nollywood and the Representation of Disability. The Global South, 7(1): 137-156 
Oyawiri, L. 2003. "Nigeria: Dwarfs lament prejudice against them", Thisday, 16 May, 2003, retrieved from http://allafrica.com/stories/200305160514.html (accessed on 25 April, 2017)

Phemister, A \& Crewe, N. M. 2004. "Objective Self-Awareness and Stigma: Implications for persons with visible disabilities". Journal of Rehabilitation, 70(2): 33-37.

Roberts, C. 2000. "Biological Behaviour? Hormones, psychology and sex". NWSA Journal, 12(3): 1-20
Wendell, S. 1996. The Rejected Body: Feminist Philosophical Reflections on Disability. New York: Routledge

World Health Organisation, 1980. International Classification of Impairments, Disabilities, and Handicaps A manual of classification relating to the consequences of disease Published in accordance with resolution WHA29. 35 of the Twenty-Ninth World Health Assembly, May 1976

Zikalala, F 1994. "Body Size and Culture", Agenda Empowering Women for Gender Equity. No. 23, Body Politics: pp. 19-22 